much that is new and is a valuable contribution to the difficult subject of the interrelationship of several Palæozoic plants exhibiting remarkable complex anatomical features.

\section{A. C. Seward}

\section{UNIVERSITY OF CAMBRIDGE}

\section{SPECIAL ARTICLES}

\section{THE BLACK CHAFF OF WHEAT}

THe continued prevalence of black chaff of wheat in the United States makes it desirable to have a Latin-scientific name for the bacterial organism causing it. This organism resembles Bacterium translucens (see Journal of Agricultural Research, Vol. XI., p. 625, 1917), cause of the bacterial blight of barley. In cross inoculations on the leaves of seedling plants the barley organism on wheat has proved either non-infectious or has produced small non-typical lesions. On the other hand, inoculation experiments have shown that the wheat organism is practically as pathogenic on barley as it is on wheat and the lesions so produced on barley are indistinguishable from those produced by the barley organism itself. There also appear to be minor cultural differences. It is suggested, therefore, that for the present, at least, the wheat organism be distinguished as Bacterium translucens var. undulosum with, in general, the characteristics already given for the species:

Var. undulosum nov. var., cause of the black chaff disease of wheat, produces yellow or translucent stripes on leaves, water-soaked or black stripes on culms, and longitudinal, more or less sunken, dark stripes or spots on the glumes. In moist weather the bacteria often ooze to the surface of the diseased spots or stripes as tiny beads or drops, drying yellowish. From sections of diseased leaves or glumes mounted in water they ooze in enormous numbers (like smoke out of a chimney) making the fluid cloudy. This organism attacks also the kernels, especially at the base causing them to be shrunken and honeycombed with bacterial pockets, but even when the kernels are not attacked their surface is liable to be infected from the diseased glumes. When the disease appears early and is severe the heads are dwarfed. Surface colonies on thin-sown agar plates are circular, pale yellow, smooth (like polished glass) and structureless on the surface, usually homogeneous also by direct transmitted light, but by oblique transmitted light (half-light) the interior is seen to be full of minute waves or interblending striations which persist, and which are best seen with a hand lens. It can be distinguished easily and quickly from accompanying non-parasitic yellow forms by this character alone. Slime copious and very pale yellow on potato agar; on whey agar very copious and bright chrome yellow-slime on this medium deeper yellow and less fluid than that of the barley organism.

Infections have been obtained repeatedly on wheat leaves and glumes. The disease is transmitted to young seedlings by way of the wheat kernels. It occurs in all the wheat states of the Middle West.

For earlier notes consult ScIEnce, N. S., Vol. XIIV., No. 1134, p. 432, 1916, the Journal of Agricultural Research, Vol. X., No. 1, 1917, and the Plant Disease Bulletin (issued by The Plant Disease Survey, Bureau of Plant Industry, U. S. Department of Agriculture), Vol. I., No. 2, 1917, and Vol. II., No. 6, 1918.

ERWIN F. SмIth, L. R. JONES, C. S. REDDY

\section{THE BUFFALO MEETING OF THE AMERICAN CHEMICAL SO- CIETY. V}

The rapid determination of titanium in titanifer. ous iron ores: JoHN WADDELL. The ore is fused in a silver, copper or iron crucible with sodium peroxide, for about ten minutes. The crucible with the fused mass is brought into a beaker with water, and the disintegrated material dissolved in sulphuric acid. Tartaric acid is added to keep the titanium in solution. Sulphuretted hydrogen is passed through the solution. If a copper or silver crucible has been used, the precipitated sulphide is filtered off, and to the filtrate, ammonia is added and more sulphuretted hydrogen is passed. To the filtrate from the iron sulphide, sulphuric acid is added and the solution is boiled to drive off the 
sulphuretted hydrogen and to coagulate the sulphur. After filtration, the solution can be made up to a given volume, and an aliquot portion taken for comparison of the color produced by addition of hydrogen peroxide, with that of a standard titanium solution. Or, the titanium may be precipitated with cupferron, and the precipitate burned and weighed as titanium oxide. A standard magnetite of the Bureau of Standards containing 0.99 per cent. $\mathrm{TiO}_{2}$ was analyzed, and the results were within a few hundredths of a per cent. of that given. Concordant results were also obtained with an ore containing between thirteen and fourteen per cent. of $\mathrm{TiO}_{2}$. Fusion of the ore with borax in a platinum crucible also gave satisfactory results, the disintegration of the fused mass being however not so rapid as when sodium peroxide was used.

The calculation of the efficiency of the silent discharge process for nitrogen fixation: F. 0 . ANDEREGG. Oxygen combines with nitrogen in the silent discharge.' The discharge evidently changes the comparatively inert molecule into a more active condition which is probably atomic. The energy required for this activation is all that is necessary for the fixation of nitrogen. The splitting up of the molecules is probably the result of electrons, which have acquired a suitable velocity by falling through a minimum potential gradient colliding with the oxygen or nitragen molecules. To calculate this energy of activation of oxygen use may be made of the fact that ultra-violet light of a wave-length shorter than $190 \mu \mu$ is completely absorbed by oxygen with ozone being formed. This corresponds to a potential gradient of about 6.4 volts using the quantum theory. Then to activate one mol of oxygen requires about 146 large calories. For nitrogen the wave-lengths have not been similarly determined but the recent work of Davis and Goucher1 makes the value of 9 volts seem to be a likely one. This corresponds to 207 calories per mol. At ordinary temperatures in the silent discharge the nitric oxide first formed is oxidized not merely to tetroxide but, because of the excess of ozone, to pentoxide, requiring one more active oxygen for this step. The complete reaction for the formation of nitric acid anhydride is then

$$
\begin{array}{r}
2 \mathrm{~N}(-207)+20(-146)+\mathrm{O}_{2}+\mathrm{O}(-73)= \\
\mathrm{N}_{2} \mathrm{O}_{5}(+1.4)+427.4 \text { ealories. }
\end{array}
$$

The numbers in brackets represent the values in large calories required for the formation of the

$$
1 \text { Phys. Rev., 13, 1-5, } 1919 .
$$

substance from the ordinary molecular condition of the elements. On an efficiency basis this amounts to about 250 grams of nitric acid per kilowatt hour. This possible yield compares fav orably with the 134 grams obtainable from the union of oxygen and nitrogen at $4,200^{\circ} \mathrm{A}$. in the purely thermal process. In practise a combination of the thermal and electrical process is used. Similarly in the formation of ozone the limiting yield is about 510 grams per kilowatt hour as compared with 80-90 grams, the best results actually obtained with an efficiency of 15-17 per cent.

The viscosity of casein solution-I., the effect of $\hat{P}_{H}$ : HARPer F. ZoLler. The study of the viscosity of casein in alkaline solutions was taken up with the ultimate object of determining its chance relationship to the adhesiveness of such solutions. Viscosity curves of Hammarsten and Dairy Division caseins dissolved in sodium hydroxide show a maximum viscosity in the region of $9.0 \mathrm{P}_{\mathrm{H}}$. The slope of the curve is very precipitous on either side of the maximum. The hydrogen-ion concentration was measured both colorimetrically and electrometrically; the Clark electrode-vessel being employed for the latter determinations.' A great significance is attached to the flattening of the viscosity curves immediately following the decline from the maximum. This is intimately correlated with the alkaline hydrolysis and evolution of ammonia in this zone. Solutions of casein in ammonia do not exhibit the precipitous decline from the maximum viscosity, although the maximum is in the same narrow region of $\mathrm{P}_{\mathrm{H}}$. The observations of Sakur, Pauli, Chick and Martin and Robertson were reviewed.

Periodic vibrations in gels: J. M. JoHLIN.

Boiling point of liquids: F. P. SoEBrL. Basing his deductions on the assumption that at the boiling point of a liquid the vilbratory energy of individual molecular constituents of the liquid and of its vapor must be equal, the author finds that the absolute temperature $T_{\infty}$ of the boiling point of an absolutely pure liquid is expressible as

$$
T_{x}=\frac{m p_{x} v x}{1.49}
$$

in which formula $m$ represents the molecular'weight of the substance or compound and $p_{x}$ and $v_{x}$ the pressure and volume of the vapor at the temperature $T_{x}$. For ordinary liquids containing impurities lowering the boiling point, the above equation reads,

$$
T_{x}=\frac{\left(p_{x} v_{x}-C\right) m}{2}
$$


$C$ being a constant, individual for each liquid; being taken at 8.7 for water and $m$ at 18 the last equation yields

$$
T_{x}=\frac{m}{1.49}\left(p_{x} v_{x}-8.7\right)=12.1\left(p_{x} v_{x}-8.7\right) .
$$

Since we calculate from tables of properties of saturated vapor of water that pvat $273^{\circ}$ absolute amounts to 31 calories per kilogram the above equation for $T_{x}$ gives

$$
12.1(31-8.7)=270^{\circ} \text { absolute }
$$

at 313 degrees at which $p v$ is 34.6 cals. we find $12.1(34.6-8.7)=313.3^{\circ}$ absolute.

At 473 degrees absolute $p v$ is equal 47.9 calories and

$$
12.1(47.9-8.7)=473.5^{\circ} \text { absolute. }
$$

Similar agreement is found for other vapors by inserting the correct valve for constant as long as no psolymerisation in the liquid takes place.

(1) Molecular state of water vapor; (2) Vapor pressure depression equation for dilute aqueous solutions: JAMES KENDALL.

Size and behavior of suspended smoke particles: R. E. WILson.

Infuence exerted by antagonistic electrolytes on, the electrical resistance and permeability of emulsin membranes: G. H. A. CLOwES.

The exact determination of molecular weights by the boiling point method: E. M. WASHBURN.

Solubility of strontium nitrate in anhydrous aloohol in alcohol containing small per cent. of water: C. W. Fousk.

(1) Influence of the age of ferric arsenate on its peptization; (2) Syneresis of silicic acids gels: H. N. Holmes.

$A$ study of the lowering of vapor pressure of water produced by absorbed $K C l$ : B. F. LovELACE, J. C. W. Frazer, V. B. Sease.

$A$ study of the lowering of vapor pressure of water produced by absorbed mannite: J. C. W. Fraser, B. F. Lovelace, T. H. Rogers.

The volume and surface of the pores in charcoal and the compression of adsorbed substances: W. D. HARkins and D. T. EwING.

An electromagnetic and valence hypothesis of heterogeneous equilibrium in adsorption: W. D. HARKINS.

DIVISION OF WATER, SEWERAGE AND SANITATION

Robert Spurr Weston, Chairman

W. W. Skinner, Secretary

Determination of bromid in mineral waters and brines: W. W. SkInNGr and W. F. Baughman.
Colorimetric methods for the determination of bromin give satisfactory results only when small quantities of bromin are to be determined. The method proposed for the determination of bromids in the presence of chlorids is the oxidation of the bromids and removal of the liberated bromid by steam distillation or by aspiration. The method depends upon the use of chromic acid for oxidation of the bromid. Chromic acid in concentrated solution liberates bromin from bromids quantitatively at room temperature and the bromin may be removed by aspiration. It liberates only a trace of chlorin from chlorids, forming probaibly chromic chlorid which remains in solution. When chromic acid acts on a solution of chlorids and bromids, some chlor-bromid is formed which is removed with the bromin by aspiration. The liberated bromin and the chlorin in the first aspiration is collected in a solution of sodium sulphite and sodium carbonate, which is evaporated to dryness and again submitted to the treatment with chromic acid and aspirated the second time. The double aspiration gives very accurate results.

Certain war gases and health: CHARLES BASKERVILLE. Evidence has been collected from all the chlorine producing plants and many works and arsenals where chlorine was used. Preponderating evidence favors the conclusion that chlorine exerts a preventative influence against influenza. The evidence is not conclusive, however, as contrary data were obtained from some plants. The contradictions may possibly be harmonized on the basis of concentration, the more dilute up to limits the more effective. Small amounts of bromine in the air appear to prevent influenza completely.

Charles I. Parsons, Secretary

\section{SCIENCE}

A Weekly Journal devoted to the Advancement of Science, publishing the official notices and proceedings of the American Association for the Advancement of Science

Published every Friday by

THE SCIENCE PRESS LANCASTER, PA. GARRISON, N. Y. NEW YORK, N. Y.

Entered in the post-ofice at Lancaster, Pa., at recond clase matter 